\title{
Article \\ \#Mathathome during the COVID-19 Pandemic: Exploring and Reimagining Resources and Social Supports for Parents
}

\author{
Frances K. Harper*(D), Joshua M. Rosenberg (D), Sara Comperry, Kay Howell and Sierra Womble \\ Department of Theory and Practice in Teacher Education, University of Tennessee, Knoxville, TN 37996, USA; \\ jmrosenberg@utk.edu (J.M.R.); scomperr@vols.utk.edu (S.C.); kadlhowe@vols.utk.edu (K.H.); \\ swomble1@vols.utk.edu (S.W.) \\ * Correspondence: francesharper@utk.edu
}

Citation: Harper, F.K.; Rosenberg, J.M.; Comperry, S.; Howell, K.;

Womble, S. \#Mathathome during the COVID-19 Pandemic: Exploring and Reimagining Resources and Social Supports for Parents. Educ. Sci. 2021, 11, 60. https://doi.org/10.3390/ educsci11020060

Academic Editor: Palitha Edirisingha Received: 29 December 2020

Accepted: 2 February 2021

Published: 5 February 2021

Publisher's Note: MDPI stays neutral with regard to jurisdictional claims in published maps and institutional affiliations.

Copyright: (c) 2021 by the authors. Licensee MDPI, Basel, Switzerland. This article is an open access article distributed under the terms and conditions of the Creative Commons Attribution (CC BY) license (https:// creativecommons.org/licenses/by/ $4.0 /)$.

\begin{abstract}
During the COVID-19 pandemic, schools abruptly transitioned to emergency remote instruction. Consequently, expectations for parental involvement in school mathematics rose to unprecedented levels. We sought to understand the experiences of parents to reimagine possibilities for engagement in mathematics during and beyond the pandemic. Leveraging data from tweets using \#mathathome and survey responses from parents, we identified who supported continued mathematics learning at home and explored the nature of the mathematics taught there. We found that Twitter and survey data sources described two largely distinct groups of those supporting parents to continue mathematics education at home, but similar findings emerged from analyses of each data source, suggesting that themes were common among different groups. Namely, we saw a commitment to continued mathematics learning and engagement with a range of mathematics topics. These topics mostly focused on elementary-level content, especially counting, through everyday activities/objects and mathematical sense-making. Most parents used resources provided by the school alongside resources they identified and provided on their own. School responses to emergency remote instruction were mostly asynchronous, and parents expressed a need for more opportunities to interact directly with their children's teachers. We discuss what the mathematics education community might learn from these experiences to support parental engagement during and beyond periods of remote emergency instruction.
\end{abstract}

Keywords: parental involvement; home-school relationships; Twitter; social media; remote learning; COVID-19; mathematics education

\section{Introduction}

In 2019, a novel coronavirus outbreak was first identified in Wuhan, China, and by early 2020, the outbreak was a global pandemic, with confirmed cases in countries throughout the world. On 11 February 2020, the World Health Organization announced an official name for the disease caused by the novel coronavirus, COVID-19 [1]. In the first quarter of 2020, infection and mortality rates rose to alarming levels across the world [2]. Social distancing, self-isolation, and travel restrictions led to a reduced workforce across all economic sectors. Jobs were lost; schools were closed down; and, financial insecurity and collapse loomed. Healthcare facilities faced shortages in space and medical supplies and the food sector faced an increase in demand due to the panic-buying and stockpiling of food products. Accordingly, citizens all over the world were emotionally and physically affected by COVID-19 during this unprecedented time of uncertainty and fear.

The impact on education was also felt around the world. In an attempt to slow the spread of COVID-19, schools abruptly transitioned to emergency remote instruction, impacting 1.5 billion students worldwide in the first quarter of 2020 [3]. Educators strove to support continued mathematics learning at home in a time of crisis, and parents and caregivers haphazardly assumed the role of teacher. Threats of deepening educational inequality rose in under-resourced schools and communities marginalized in and by mathematics. 
In response to these educational crises, we sought to understand the experiences of parents and caregivers during the initial shift to emergency remote instruction. In doing so, we hoped to help the mathematics education community to (re)imagine ways to support families in mathematics during and beyond the COVID-19 pandemic. In early 2021, at the time of writing, the COVID-19 outbreak continued to cause significant disruptions for families (e.g., physical and mental health, financial security, childcare availability) and society (e.g., economic stability, healthcare systems). This work is timely and important because education continues to experience significant disruptions, and remote instruction remains vital in many countries.

In summer and fall 2020, schools were beginning to move beyond emergency remote instruction by considering ways to more effectively support mathematics learning remotely, and we wondered what might be learned from the initial emergency transition to mathematics education in students' homes to inform broader access to and support for high-quality remote mathematics instruction. To (re)imagine mathematics education during a global crisis, we analyzed the various online or otherwise remote (from the school) resources that families and educators utilized to further support engagement in mathematics at home. Accordingly, we asked:

RQ1: What was the nature of available resources (e.g., source, mathematical focus) for continued mathematics education at home? Which did parents use during emergency remote instruction, and how did they use them?

RQ2: Who were allies for parents (e.g., teachers, friends) in supporting continued mathematics education during emergency remote instruction, and how were they offering support?

Looking across findings from these two research questions, we considered implications for the types of resources and supports that might prove useful as schools and families continue to manage mathematics education remotely and how to broaden access to those resources and supports.

\subsection{Background}

Educators doubtlessly play a critical role in mathematics learning. Accordingly, efforts to broaden opportunities largely focus on school mathematics. School-based initiatives, however, often overlook how parents are uniquely positioned to advocate for and support children's mathematics education across educational contexts. For example, within the United States (U.S.), a recent campaign to "catalyze change" in mathematics mentions parents only four times [4,5]. This is worrisome because parental involvement is strongly linked to children's mathematics achievement [6-8]. Moreover, all the adults in children's lives shape children's mathematics identities-how children see themselves as learners and doers of mathematics-by endorsing or challenging cultural stereotypes about who is "good" at mathematics [9]. Those from privileged backgrounds have long used parental involvement as a form of social capital to ensure their children's achievement [8]. Parents of students historically marginalized on the basis of race, gender, and class, however, face unique challenges to involvement in mathematics education. For example, they must navigate stereotypes that position them as disinterested in or incapable of supporting mathematics learning because of low educational attainment. These stereotypes, paired with under-recognized forms of involvement, overlook how parents from marginalized groups deliberately advocate for and support their children's mathematics education [10,11].

Parents from marginalized groups value their children's mathematics education and are committed to supporting it [12]. Direct invitations, inclusion in decision making, and reengagement with mathematics can mediate increased parental involvement [13-15]. Reengagement with mathematics is especially promising because differences between parents' own mathematics education, which likely emphasized rules and procedures [11], and the curriculum and instruction experienced by their children present barriers to parental involvement, even in early elementary levels [16]. Helping parents understand the evolution of school mathematics can build parents' capacity to support their own children's mathe- 
matics education and also allow them to be allies for other parents [17]. To support parental involvement in our local community, Harper launched family workshops in Fall 2019 in an effort to support parents from marginalized groups to act-more effectively-as "intellectual resources" in mathematics education [15]. As these efforts were just beginning to ramp up, the COVID-19 global pandemic disrupted life within the U.S. Countries around the world had already felt the devastating impacts of the pandemic as hospitals were overwhelmed and illness and death rates surged. In response, universities and schools across the U.S. closed and/or transitioned to emergency remote instruction [18].

Parents were suddenly thrust into unprecedented levels of engagement with school mathematics as they became responsible for ensuring their children's continued mathematics learning. Within our context, we recognized that the pandemic created additional challenges to parental engagement—such as parents working outside the home, caring for sick family members, and managing racially based disparities. For example, African American communities were facing alarmingly and disproportionately high rates of infection and death from COVID-19 [1]. Structural inequities make Black Americans less likely to work jobs possible from home or to have medical insurance, but more likely to have medical conditions that increase risk [19]. Furthermore, Black and Latinx households in the U.S. are less likely to have the technology necessary to engage with online instruction offered by schools [20], and as educational responsibilities increased for parents, mothers experienced a disproportionate rise in unpaid care work [21]. Individuals from groups marginalized on the basis of race, gender, and class felt the impacts of the pandemic more heavily and consequently reported higher rates of major negative mental health impacts $[21,22]$.

We were worried about long-term impacts and the potential for deepening educational inequality with respect to mathematics but found ourselves less able to connect with families in our community. The need for support was heightened, but parents' access to resources and allies became more limited. In addition to our canceled workshops, other supplemental academic programs (e.g., tutoring, after-school programs) at schools and community organizations vanished. Accordingly, we undertook this study with the hope of discovering ways both for our team and other mathematics educators to address the greatest needs of parents in a time of significant disruption to the educational system.

\subsection{Theoretical Framework}

A traditional view of parental engagement focuses on what parents do to support their own child's educational development and how often they participate in activities organized by the schools, such as parent conferences and school events [23]. In contrast, we recognize that parental engagement extends beyond individual families and schoolinitiated activities and, instead, frame parental engagement as "a set of relationships and actions that cut across individuals, circumstances, and events that are produced and bounded by the context in which that engagement takes place" ([10]; p. 6). In other words, parental engagement must be understood through both what parents engage in and how they manage to do so. This framing problematizes a linear view of parental engagement (i.e., parents $\rightarrow$ mediation (e.g., parent conferences) $\rightarrow$ involvement), instead emphasizing relational aspects and parents' agency.

Drawing on cultural-historical activity theory and critical race theory, Calabrese Barton and colleagues [10] proposed an ecological model for parent participation in education. Applying this model to our current study allowed us to understand mathematics education as it was happening in different spaces. This was especially useful given that COVID-19 pushed mathematics education out of the typical school context and into home and online spaces. Emergency remote instruction also significantly changed the roles and division of labor among teachers and parents, rules for parents' participation in school mathematics, the tools and artifacts used for mathematics learning, and the communities and other individuals who parents relied on to mediate engagement. Our chosen theoretical framework provided a powerful way to consider how each of these changes allowed for a unique type of parental engagement during COVID-19 emergency remote instruction, un- 
derstood as parents' mediation of space (e.g., home, online) and capital (i.e., human, social, and material resources and supports) in relation to others in school settings (e.g., teachers). Figure 1 shows an adaptation of the original ecologies of parental engagement model [10] for our study of parents' role in mathematics education during COVID-19 emergency remote instruction.

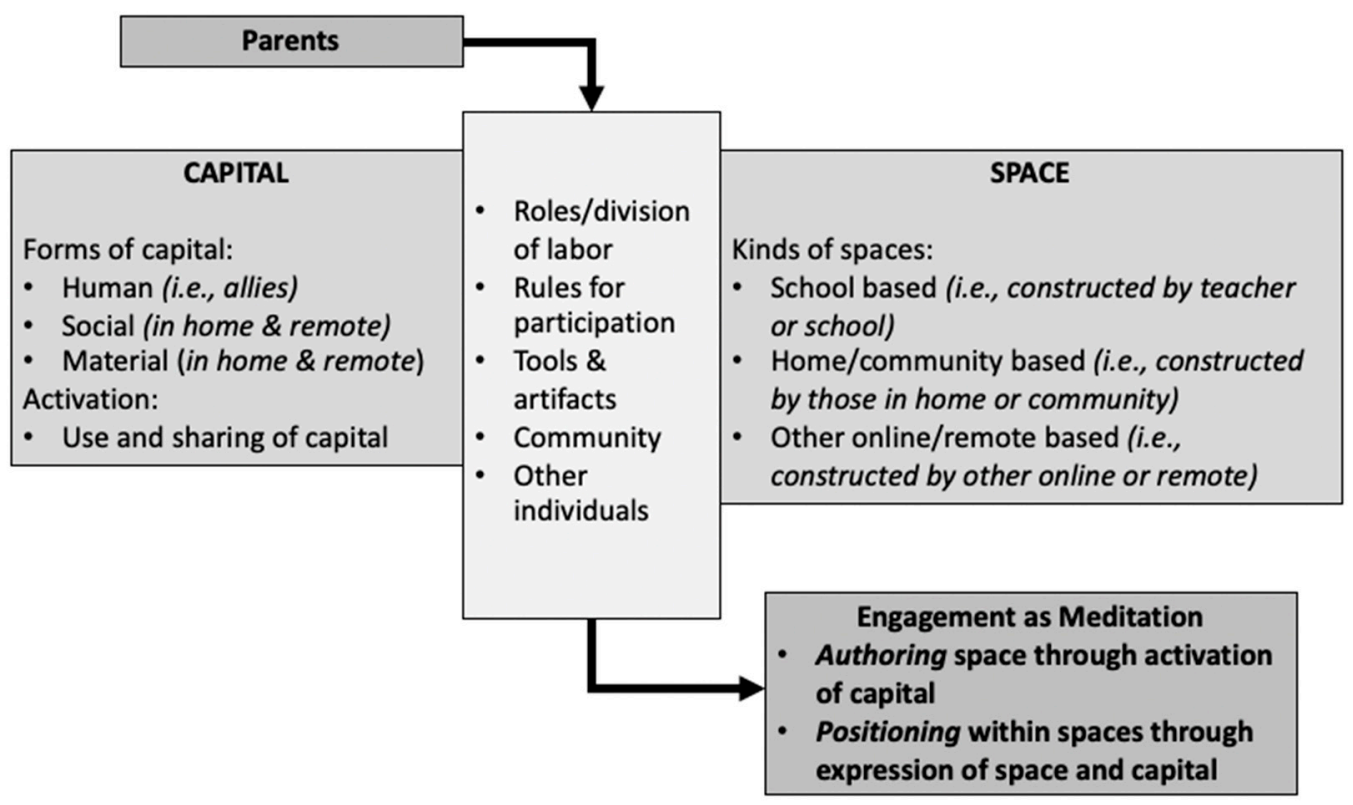

Figure 1. Adaptation of Ecologies of Parental Engagement Framework for COVID-19 Emergency Remote Instruction.

Across both research questions, we sought to understand parent engagement as authoring space (i.e., continued mathematics education in the home) through activation of various forms of capital. More specifically, with RQ1, we explored the nature of available spaces for authoring emergency remote mathematics instruction, including spaces constructed by teachers/schools (e.g., worksheets, learning management systems), by parents/communities (e.g., games, informal learning), and by other online or remote sources (e.g., social media). We aimed to identify the forms of capital available within each space and to better understand parents' activation of that capital. The second research question focused specifically on parents' activation of human and social capital, given the significant disruption to both due to the unique social isolation required during COVID-19 emergency remote instruction.

\section{Materials and Methods}

This study drew on a parallel convergent mixed methods research design, in which qualitative and quantitative data generation and analysis occurred simultaneously but independently [24]. The different methods were weighted equally, and results were interpreted together to describe how parents mediated different spaces and forms of capital to support the continuation of mathematics education in the home during emergency remote instruction.

\subsection{Data Sources and Measures}

To explore what spaces and forms of capital (RQ1), especially allies (RQ2), parents had available and used, we relied on two primary data sources: (1) data generated from posts on social media, namely Twitter, that promoted mathematics at home during COVID-19 emergency remote instruction and (2) data generated from a survey of parents about their experiences with emergency remote instruction. Use of these two different data sources was important because, taken together, they provided a wider snapshot of experiences with mathematics at home during emergency remote learning. The first data source of- 
fered a look into social media spaces, which provided social and human capital through access to expert educators and other parents and material capital in the form of mathematics activities and content. The second data source was important for identifying the forms of capital available in more traditional spaces, such as school-constructed spaces and the home/community setting. Moreover, survey data helped us to understand the ways in which parents activated the various forms of capital across the three different available spaces (school, home/community, online) in order to author their engagement with continued mathematics education in the home during emergency remote instruction.

\subsubsection{Twitter Data Generation}

We first completed an exploratory review of various social media platforms (e.g., Facebook, Twitter) before we narrowed our data generation to Twitter because data were readily available and most relevant to our research questions (i.e., focused on parents, not teachers). Twitter is a common social media platform for people of all ages across the world to interact and connect with each other. Twitter allows users to hear and see what other individuals are talking about through videos, images, and text, known as tweets. Users can post their own tweets or comment on other users' tweets to share advice, their thoughts and opinions, or ask questions. Users can also share tweets posted by others (i.e., retweets) on their own profile pages. Twitter users customize and personalize their timeline (the tweets that show up when they log into Twitter) by following other users that have similar interests through sharing insights, ideas, or methods. Twitter also utilizes \#hashtags throughout the platform. Users can add a \#hashtag to their tweets, and \#hashtags organize discussions that users are having on Twitter and allow for other users to join the conversation. Users can look for a topic specifically by searching a \#hashtag in the search bar.

Several \#hashtags are popular among mathematics educators (inclusive of researchers, teachers, teacher educators) in the U.S. and beyond. For example, \#iteachmath and \#MTBoS are widely used. Anyone can create a new \#hashtag, and mathematics educators sometimes create specific \#hashtags to facilitate discussion on Twitter at specific dates and times. The Twitter platform provides resources for parents and educators to connect. Parents and educators can see what other educators are implementing in their classrooms, methods they use for teaching, activities, and various materials that can be helpful to promote mathematics learning. By using tweets from organizations, educators, or other parents, parents can find ways to support their children in mathematics in school and at home. This potential use of the Twitter platform became especially salient during COVID-19 emergency remote instruction.

We decided to focus on the forms of capital provided through \#mathathome (a subset of the Twitter space) in this study. This specific \#hashtag allows users and parents to see how educators and other parents are collaborating and supporting mathematics learning at home. By seeing what other users are doing with mathematics at home, parents could model and incorporate the same practices and activities in their home. If parents needed further support, they could leave a comment on the tweet or message the user. Twitter opens a virtual world full of information that can help to provide support for parents in their child's learning.

To analyze Twitter data using \#mathathome, Harper used NCapture (NVivo 12 Version 12.6.0) [25] to generate a dataset of \#mathathome tweets from 13-23 April 2020, which included 160 unique tweets, along with the content of tweets and additional information (e.g., username, biography, location) for each tweet. Harper exported tweet content into a document for qualitative analysis in Dedoose (Version. 8.3.17) [26], a web-based platform. To collect additional tweets, Rosenberg set up automatic data generation of tweets containing \#mathathome from 22 April through 21 May 2020 using a Twitter Archiving Google Sheet (TAGS) [27] ( $n=246$ tweets) for quantitative analyses. These timeframes were chosen because families and schools were involved in emergency remote instruction. 
Due to the different ways in which we generated data, we then used the rtweet package [28] for the R statistical software [29] to further process the tweets from the two sources for use in subsequent analyses. This step resulted in a combined dataset with 406 tweets and 90 variables for each tweet (including the text of tweet, screen name and profile for user, date, and other information, such as the number of retweets). These tweets were sent by 228 individuals, with 46 individuals posting two or more tweets. Additionally, we constructed a number of measures from these data, described as follows.

\subsubsection{Survey Data Generation}

The research team collaboratively developed a survey of parents' experiences with mathematics at home during COVID-19 emergency remote instruction. We framed questions based on previous experiences with families, on conversations with parents since schools had closed, and on preliminary analyses of Twitter data. The survey included four sections: (1) the transition to emergency remote instruction; (2) doing mathematics at home, generally; (3) social and human capital (i.e., allies) for mathematics at home; and (4) demographic information (Table 1). Most questions involved multiple-choice options, but also included an option to write in a response. Each section included at least one open-ended question to provide opportunities for parents to elaborate on their experiences.

Table 1. Overview of measures used across the four sections of the survey: (1) the transition to emergency remote instruction; (2) doing mathematics at home, generally; (3) social and human capital (i.e., allies) for mathematics at home; and (4) demographic information.

\begin{tabular}{|c|c|c|c|c|}
\hline Section & Measure 1 & Measure 2 & Measure 3 & Measure 4 \\
\hline 1 & School or district supports & $\begin{array}{l}\text { Use of school-provided } \\
\text { resources }\end{array}$ & $\begin{array}{l}\text { Use of online } \\
\text { learning systems }\end{array}$ & $\begin{array}{l}\text { Additional supports } \\
\text { needed (open-ended) }\end{array}$ \\
\hline 2 & $\begin{array}{l}\text { Confidence with } \\
\text { math education }\end{array}$ & Parent-provided resources & $\begin{array}{l}\text { Presence of math } \\
\text { at home }\end{array}$ & $\begin{array}{l}\text { Types of math at home } \\
\text { (open-ended) }\end{array}$ \\
\hline 3 & $\begin{array}{l}\text { Allies in supporting math } \\
\text { (e.g., teacher, friend) }\end{array}$ & $\begin{array}{l}\text { Social media engagement } \\
\text { (platform, frequency) }\end{array}$ & $\begin{array}{l}\text { Additional comments } \\
\text { (open-ended) }\end{array}$ & \\
\hline 4 & $\begin{array}{l}\text { Child's grade level and } \\
\text { school type }\end{array}$ & $\begin{array}{c}\text { Parent's education level } \\
\text { and current } \\
\text { employment status }\end{array}$ & $\begin{array}{l}\text { Age, gender, and } \\
\text { race/ethnicity }\end{array}$ & Global region \\
\hline
\end{tabular}

We piloted our survey with three parents and refined questions, especially demographic questions, to be inclusive of diverse experiences [30]. We made all survey questions optional so as to place the least amount of burden on parents during an already challenging time. The survey was distributed through Google Forms using a convenience, snowball sampling approach [31], which is appropriate given that pandemic conditions made parents a "hard-to-reach" population.

\subsection{Participants}

Participants included two groups corresponding to the two data sources, Twitter users and survey respondents. The tweets were posted by 228 unique participants. While some \#mathathome participants were very active (posting more than 40 tweets in one case), on average, participating individuals posted around two tweets $(M=1.78, S D=3.33)$. Survey respondents included 101 parents; 81 were from North America, 17 from Australia/New Zealand, and one each from Europe, Asia, and unspecified. Table 2 displays remaining demographic information of the participants in our survey sample, including participants race/ethnicity, highest education attained, and age; we provide this information to aid in interpreting (and contextualizing) our findings. Though both purposefully selected (and non-probability-based), these samples allowed us to understand the experiences of a select group of individuals-mostly parents, especially those in the U.S. Thus, findings 
from this study generalize only in a limited way: primarily to parents (and others, in the case of the Twitter) in the United States sharing salient features with those in our samples.

Table 2. Self-reported demographic information of survey participants $(n=101)$. Note: Shading indicates participants belonging to the larger group of people of Color.

\begin{tabular}{|c|c|c|c|c|c|c|}
\hline \multirow{2}{*}{$\begin{array}{c}\text { Gender } \\
\text { Race/ } \\
\text { Ethnicity }\end{array}$} & \multicolumn{2}{|c|}{ Woman: 92} & \multicolumn{2}{|c|}{ Man: 7} & \multicolumn{2}{|c|}{ Prefer Not to Say (PNS): 2} \\
\hline & $\begin{array}{c}\text { White } \\
73\end{array}$ & $\begin{array}{c}\text { Black } \\
9\end{array}$ & $\begin{array}{l}\text { Two or more } \\
\text { races } \\
5\end{array}$ & $\begin{array}{l}\text { Asian } \\
5\end{array}$ & $\begin{array}{c}\text { Hispanic/Latinx } \\
\text { (any race) } \\
4\end{array}$ & $\begin{array}{c}\text { PNS or other } \\
5\end{array}$ \\
\hline Highest & Masters & Doctorate & Bachelors & High School & Other & PNS \\
\hline Education & 42 & 26 & 22 & 8 & 2 & 1 \\
\hline Age & $\begin{array}{c}18-35 \\
13\end{array}$ & $\begin{array}{c}36-40 \\
28\end{array}$ & $\begin{array}{c}41-45 \\
37\end{array}$ & $\begin{array}{c}46-50 \\
11\end{array}$ & $\begin{array}{c}51+ \\
10\end{array}$ & $\begin{array}{c}\text { PNS } \\
2\end{array}$ \\
\hline
\end{tabular}

\subsection{Data Analysis}

We first describe the independent qualitative and quantitative analyses for the Twitter and survey data, followed by a summary of how the analyses and the resulting findings were weighed and interpreted equally together to describe how parents mediated different spaces and forms of capital to support the continuation of mathematics education in the home during emergency remote instruction.

\subsubsection{Qualitative Analysis of Tweets}

To understand the nature of the resources (i.e., human and social capital) available on Twitter (i.e., the space) for supporting mathematics at home (RQ1), we categorized the tweet content through iterative rounds of qualitative analysis [32]. Harper, Comperry, Howell, and Womble analyzed the first twenty unique tweets to develop a codebook that described the nature of resources (i.e., material capital) provided in each tweet by mathematics topics (e.g., number, algebra), mathematics practices (e.g., justifying; multiple strategies), and grade level (e.g., elementary/primary, high school/secondary). Codes were exhaustive but not mutually exclusive. For example, some tweets addressed multiple mathematics topics, and we only applied grade level codes when users explicitly indicated a target grade. Analysis began with each researcher applying codes separately. Next, we met to reach consensus on definitions and applications of codes. We then repeated this process to finalize coding of tweets.

In the next phase, Comperry, Howell, and Womble independently applied codes to different sets of twenty-five unique tweets (total $n=75$ ). We also added participants professional role and parent (described below in quantitative analysis of tweets) to the codebook in order to address who was providing support for mathematics at home (RQ2; i.e., human and social capital), after which Harper applied these codes retroactively to the first twenty-five tweets. Then, we reached consensus and discussed necessary additions to the codebook. In a final round of analysis, Comperry, Howell, and Womble reviewed the previously coded tweets for (dis)agreement and divided up the next thirty tweets for independent coding. Finally, we met to reach consensus on all coding. As no additional codes were necessary in the last round, we assumed data saturation (i.e., our codebook sufficiently described the content of tweets), and the remaining thirty tweets were not coded.

\subsubsection{Quantitative Analysis of Tweets}

To understand the forms of social and human capital available through Twitter, we first geocoded individuals' self-reported locations (from Twitter profiles) using the mapsapi $\mathrm{R}$ package [33]. We could obtain locations for 194 of the individuals who participated in \#mathathome using a geocoding method determined to be sufficiently accurate for identifying the state (and therefore the country) participants are from [34]. We created a map with the geocodes of users' locations (see details in Results), and then used this map 
to aid our interpretation of the geographic location of active participants, as well as these users' professional roles.

To determine users' professional roles, we used a coding frame (for the professional role of participants in state-based educational Twitter hashtags) that was previously developed and applied to study educational networks [35]. This coding frame included codes for teachers, instructional coaches, researchers, and other roles. As an example of applying this coding frame, a participant with the following biography was coded as a teacher: "K/Gr.1 teacher at [name removed] School. Math coach. Focusing on playful math \& literacy instruction." As another example, the following participants' profile was coded as an organization: "[name removed] is a \#nonprofit building understanding \& love of \#math in students and educators. Follow us for \#mathed news + resources!".

Rosenberg applied these codes to profile descriptions of all individuals who posted two or more tweets, as those who posted only a single tweet were likely less critical to our understanding of \#mathathome. Of the 46 individuals who posted two or more tweets, seven were unable to be coded (because individuals' profile descriptions provided limited information or individuals' professional roles were unclear). We also coded professional roles alongside qualitative coding of tweet content (as described above). Finally, we used individuals' profile descriptions and content of their tweets to determine whether they identified as a parent.

From users' professional role and data on the interactions that took place through \#mathathome, Rosenberg calculated the number and proportion of individuals in each role and location and carried out social network analysis, using the resulting visualizations (Figure 2) to aid in our interpretation of which professional roles were most active (and with whom they were interacting). In this visualization, the size of the nodes (the circles or triangles) represents the number of tweets the user sent to \#mathathome, with larger nodes representing a greater number of tweets sent. The nodes also represent users' professional role (through color) and parental status (through the shape of the node, with a triangle representing a user with a particular professional role who also identified as a parent). Edges, or lines between users, represent interactions, with more heavily weighted (wider) lines representing a greater number of interactions between any pair of individuals.
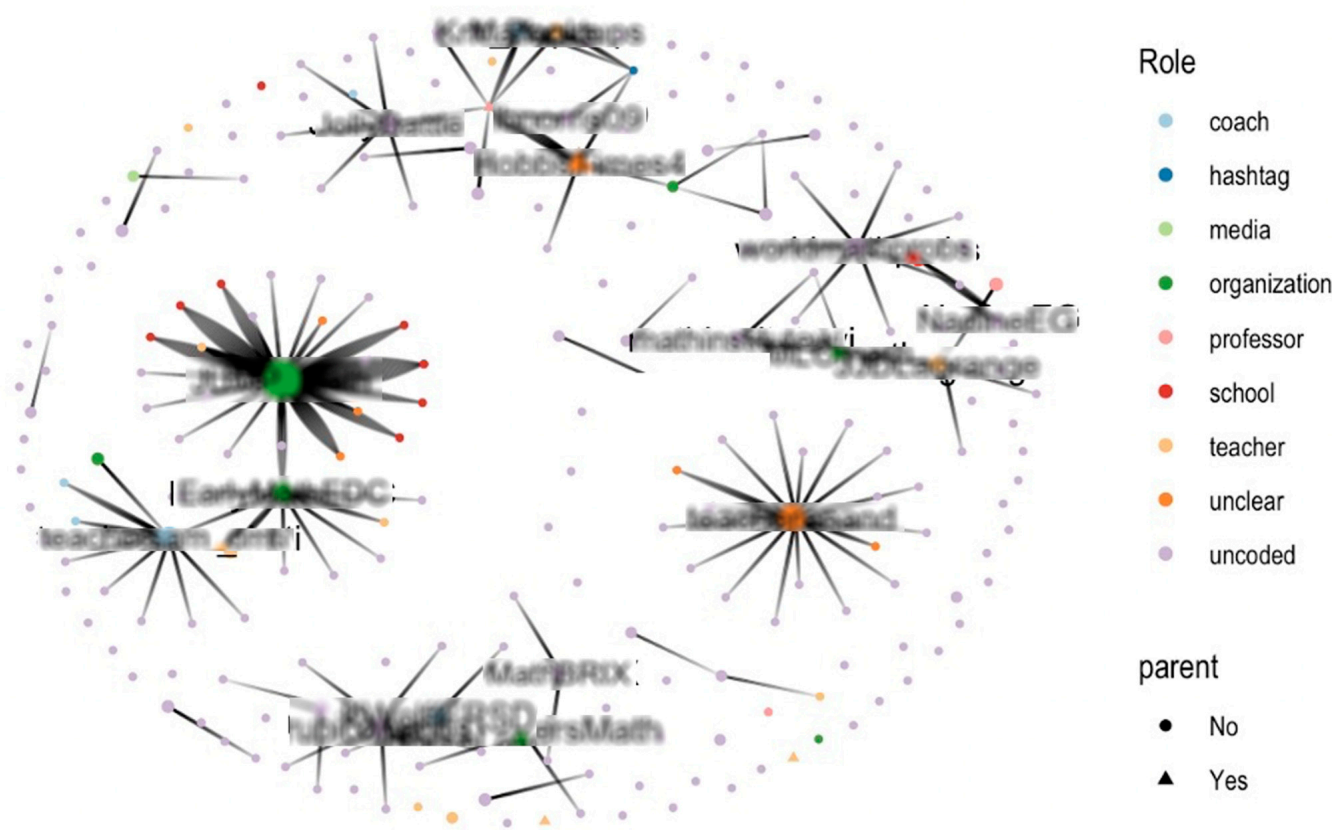

Only those who posted one or more original tweets are included

Figure 2. Sociogram (Network Visualization) of \#mathathome Interactions for Key Users. Note: We added a distortion to the above figure for inclusion in this manuscript to protect the privacy of participants. 
The resulting sociogram provides some insight into the activation of social and human capital available through the \#mathathome space by other Twitter users. Accordingly, we calculated a network statistic, namely the degree centrality, which represents the number of interactions-replies, retweets, quotes, and mentions-an individual initiated and received, of participants, and we explored the posts of the three most central participants in greater depth by examining themes from qualitative analysis of their tweets.

\subsubsection{Qualitative Analysis of Survey}

Harper, Comperry and Womble worked separately to analyze the open-ended responses through iterative rounds of qualitative coding in Dedoose. All researchers used the existing codebook when possible to allow for comparisons across data sources. Harper analyzed responses to questions on the social media platforms used ( $n=30$ responses; RQ2-who is providing support; i.e., human and social capital via social media) and to a request for general comments ( $n=34$ responses; RQ1 \& 2). Analysis required new coding categories for type of social media resource (e.g., hashtag; blog; RQ1—source of resources; i.e., online space). Comperry analyzed responses to a question about mathematics topics and activities ( $n=89$ responses; RQ1-nature of resources; i.e., material capital). This analysis largely relied on existing codes with a new category for different types of activities (e.g., cooking). Womble analyzed responses to a question about what supports would be helpful ( $n=84$ responses) to help us (re)imagine spaces and forms of capital for remote mathematics education based on findings. This analysis rarely overlapped with the codebook, and Womble created a category for teacher and school supports (e.g., offline materials, synchronous instruction; RQ1-source and type of resources; i.e., human and social supports in different spaces). All researchers discussed each independent analysis in order to identify broader themes.

\subsubsection{Quantitative Analysis of Survey}

Rosenberg and Howell analyzed survey responses quantitatively using Microsoft Excel and R. We calculated descriptive statistics on who is engaging children in at-home mathematics activities in order to understand the demographics of respondents (RQ2), and the grade level of children to provide insight into the ages of students. This information provided insight into the nature of mathematics topics appropriate for at-home learning (RQ1; i.e., material capital). Additionally, based on our knowledge of prior research recognizing the ubiquity of math at-home activities amongst underrepresented groups, we analyzed questions on doing mathematics at home and parents' educational levels attained and their race/ethnicity. To do so, we cross-tabulated responses to the question on doing mathematics at home with demographic responses for parents' educational level and race/ethnicity. This analysis was aimed at identifying any differences in the mediation of space and capital by different groups of parents.

\subsection{Interpreting Results}

To interpret results together, we created data displays from all analyses. Quantitative data displays included sociograms, maps, charts, and tables, and qualitative data displays included tables showing code frequency by data source, co-occurrence of codes, and illustrative excerpts and tweets. Comparing findings from the two data sources (i.e., Twitter, survey) was essential to our broader understanding of the parental engagement with COVID-19 emergency remote mathematics instruction, namely, the unique mediation of spaces and capital during a time of global crisis. Interpreting findings from both data sources together allowed us to confirm and disconfirm themes about engagement with mathematics at home that emerged from each data source and types of analyses. For example, the mathematical nature of resources (i.e., material capital from school or home spaces) described in surveys was often vague (i.e., naming a broad domain of mathematics), but data from tweets provided specific mathematics tasks (i.e., material capital from online space). We used the survey analysis to identify which broad mathematics domains parents 
identified as important (i.e., which forms of material capital they sought to activate) and the Twitter analysis to identify more specific mathematics topics within those broader domains most likely addressed at home. We further discussed and compared data displays in relation to our research questions and theoretical framework to arrive at the broader themes presented next. Overall, we aimed to provide qualitative, descriptive insights into how parents mediated various forms of capital across different spaces for engagement with mathematics at home during emergency remote instruction. We certainly do not claim that our findings generalize to all parents, but we feel confident that the findings describe experiences that reflect common successes and challenges in parental engagement during emergency remote instruction.

\section{Results}

We found that Twitter and survey data sources described two largely distinct groups of allies (i.e., forms of human and social capital) supporting parents to continue mathematics education during COVID-19 emergency remote instruction. \#mathathome tweets came mostly from teacher and educational organization allies, while survey respondents primarily named allies working offline (RQ2). As this study is descriptive (not inferential), we see these differences as a strength that captured broader perspectives across multiple stakeholders in emergency remote mathematics instruction. Despite differences in participants across online and offline spaces, similar findings emerged from analyses of each group's activity (i.e., the activation of capital). Broader themes about the nature and use of resources for remote mathematics instruction (RQ1) showed:

- Engagement with a range of mathematics topics, which mostly focused on elementarylevel content, especially counting;

- A commitment, across demographic groups, to supporting children's continued mathematics education through everyday activities/objects and mathematical sense-making;

- A combination of resources provided by the school alongside resources parents identified and provided on their own;

- Reliance on mostly asynchronous instructional resources.

\subsection{Who Was Involved in Mathematics at Home}

Findings in this section provide insights into who (parents and allies) supported the continued mathematics education of children during the COVID-19 emergency remote instruction (RQ2). As mentioned above, our two data sources provided insights into the various forms of human and social capital leveraged by parents during emergency remote mathematics instruction. First, we present our findings about the human and social capital available to parents across both online (Twitter) and offline (school-constructed, home/community) spaces. We provide additional details about the teachers and other educational allies accessible to parents through Twitter. Then, we discuss what the survey results revealed about parents' activation of various forms of human and social capital in continuing mathematics education in the home.

\subsubsection{Twitter Users}

Across social media posts to \#mathathome on Twitter, for participants who sent two or more tweets, teachers made up the plurality of participants $(n=12 ; 21 \%)$, followed by accounts for schools $(n=7 ; 15 \%)$ and educational organizations $(n=7 ; 15 \%)$. Instructional coaches and administrators $(n=6 ; 13 \%)$, faculty at universities $(n=3 ; 7 \%)$, and accounts for mathematics education-related hashtags $(n=1 ; 2 \%)$ and a media outlet $(n=1 ; 2 \%)$ made up the remaining accounts that were able to be coded. While teachers made up the largest group of users, the social network analysis revealed that the most active users were two educational organizations (centrality $=296$ and 56, representing the numbers of replies, retweets, quotes, and mentions that each user received) as well as a teacher (centrality = 82), suggesting that although there were fewer organizations than teachers involved in \#mathathome, these organizations were central, and therefore potentially 
influential to others. Only three users were identified as parents on the basis of their profile information.

Twitter participants were located in North America (U.S. $(n=101)$, Canada $(n=49)$, and Mexico $(n=5))$, as well as Europe (The U.K. $(n=6)$, France $(n=5)$, Germany $(n=3))$, India $(n=8)$, and Australia $(n=2)$. Six other countries had a single participant (Figure 3 ). As is depicted by the size of the circles in Figure 3 (with larger circles representing a greater number of tweets posted by individuals), the most active participants were located in the U.S., Canada, and India.

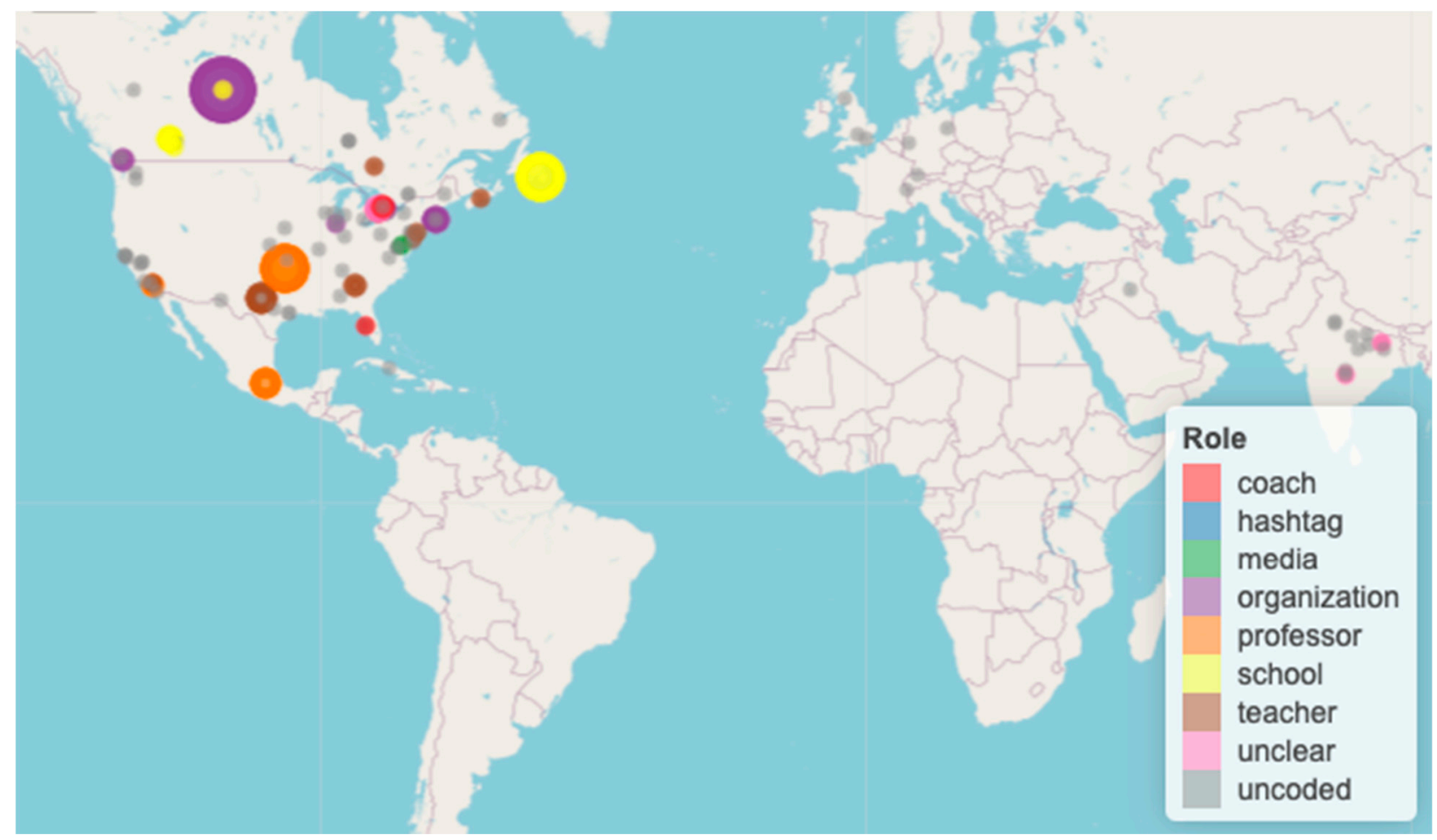

Figure 3. Geographic locations and professional roles of \#mathathome participants. Note: Circles represent individual users who posted to \#mathathome. The size of the circles depicts the number of tweets they sent to the hashtag.

Qualitative analysis of Twitter data showed that the mathematical content of posts was overwhelmingly targeted to an audience of parents of elementary-aged children. Explicit references to grade level primarily mentioned early $(n=21)$ and late elementary $(n=14)$ grades and preschool $(n=8)$ but only a few for middle $(n=3)$ or secondary $(n=1)$ grade levels.

\subsubsection{Survey Respondents}

Quantitative analysis of survey responses provided insights into who was engaging children in mathematics at home, where a similar trend regarding grade level emerged. Most respondents were parents of elementary-aged children $(n=73)$, compared to middle grades $(n=20)$, secondary $(n=4)$, and preschool $(n=7)$. Children largely enrolled in public schools $(81 \%)$, with only $14 \%$ enrolled in private schools and $5 \%$ enrolled in other types of schools, often those receiving public funding (e.g., Catholic).

Ninety percent of parents reported doing mathematics at home with their children, and most parents reported that they were very confident $(n=60)$ or confident $(n=22)$ in supporting their children's mathematics learning. Some parents explained in open-ended responses that they felt confident supporting mathematics at home because they were mathematics educators themselves, but other mathematics educators identified challenges (shared with other, non-educator parents) faced in ensuring continued mathematics learning during COVID-19. For example, one teacher-parent explained: "Doing math with my 
child is painful and has led to frustrations and melt-downs ... Until COVID-19, I typically avoided helping her with the occasional math homework ... doing math at home has been brutal." Parents, teachers, and non-teachers alike identified a lack of familiarity with school-based methods or developmentally appropriate mathematics as reasons they felt less confident in supporting mathematics learning at home: "I have taught middle school math for 15 years, but don't necessarily know what is developmentally appropriate for my Kindergartener," and, "they don't teach addition like I used to do it at school and I don't want to interfere in his method".

When we divided respondents into two groups by education level (high, representing the attainment of a Bachelor's degree or an advanced degree, and low, representing graduating from high school or reporting another educational credential) and race/ethnicity (white; people of Color), we found that, overall, $91 \%$ of respondents are highly educated and $22 \%$ are people of Color (see gray highlights in Table 2 above). Only nine parents made up the group of respondents with low levels of education, and $55 \%(n=5)$ were also people of Color (i.e., over half of the individuals from lower educated backgrounds are people of Color). Above, Table 2 shows the percentage of parents by education level and race/ethnicity who reported engaging in mathematics at home with their children.

Descriptions of parents' confidence in and willingness to support mathematics at home varied. One parent noted: "I am very involved in my child's math education. My own level of math education is a [high school graduate] level, therefore, I am capable in providing any support necessary," while another parent shared, "My children are in primary. I'm already struggling to remember and keep up." We concluded, however, that race and education level did not help to explain differences in parents' confidence or willingness to support mathematics at home.

Survey responses concerning parents' social media use bolstered the case for \#mathathome users and survey respondents reflecting different uses of social and human capital, as just over two-thirds- $64 \%$ - of parents said they never used social media for mathematics education. As one parent described, "I was not aware this was a thing people do. Interesting ...". Moreover, those who reported using social media for mathematics at home did so only occasionally $(26 \%)$, with $10 \%$ reporting monthly, weekly and daily use.

Responses provided insights into parents' allies (RQ2; social and human capital) and resources (RQ1; material capital; spaces) for engaging with mathematics at home. YouTube was the most popular resource $(n=20)$, followed by Facebook $(n=12)$, Pinterest $(n=8)$, and Twitter $(n=6)$, suggesting that when parents used social media and related resources, they were likely to turn to spaces other than Twitter. Qualitative analysis showed that parents tended to identify specific blogs or sites by individuals or educational organizations over social media hashtags or groups. Some examples included: Math Mammas (https:/ /blogs.ams.org/mathmamas (accessed on 9 October 2020)), Khan Academy, and YouCubed (https: / / www.youcubed.org/ (accessed on 9 October 2020)). Parents did not mention \#mathathome among Twitter hashtags; hashtags mentioned included: \#MTBoS, \#iteachmath, and \#MathArtChallenge (mentioned 2-3 times by respondents) and \#WODB, \#unitchat, \#mathforkids, and \#tmwyk (each mentioned once).

Finally, parents overwhelmingly reported turning to their child's teacher as an ally $(n=76)$. Other allies included a partner or spouse $(n=57)$, a child's older sibling $(n=29)$, other adults at child's school $(n=26)$, other parents $(n=21)$, and other family members $(n=19)$. Less common allies included tutors, community organizations, and members of professional networks. Only seven parents said they did not feel like they had any allies for mathematics education.

\subsection{Nature of Mathematics at Home}

Mathematics content emphasized through both \#mathathome tweets and in parents' survey responses provided a way to understand the nature of continued mathematics education in the home during COVID-19 (RQ1; how capital was mediated in different spaces). In this section, we present results from comparing findings across the two data 
sources (i.e., Twitter, survey). Accordingly, findings are organized by broader themes about families' experiences with COVID-19 emergency remote mathematics instruction, namely the mathematical focus and responses to and resources during COVID-19. In the discussion section, we further elaborate on the importance of interpreting results from both data sources together in order to understand families' experiences with mathematics at home during the early stages of the pandemic. For example, parents named only broad mathematics topics (i.e., naming a broad domain of mathematics), but data from tweets provided insight into specific mathematics activities at home related to those topics.

\subsection{1. \#Mathathome Mathematical Focus}

We found opportunities for engagement with a range of broad mathematics topics, including (in order of frequency): number and quantity; data and statistics; geometry; four operations; fractions; algebra; measurement; and calculus (i.e., material capital). Those tweets focused on number and quantity - the most common topic for \#mathathome tweets-overwhelmingly presented opportunities for counting, with less—but still someattention to counting by multiples, place value, money value, and estimation. Sometimes, users prompted families to count using a picture provided directly through a post on Twitter. For example, families were asked to count how many in an image of a bridge and describe how they counted (Figure 4, left). Oftentimes, users encouraged family members to count physical objects found in the household or in everyday activities. For example, users challenged families to find their own pictures to post and count (Figure 4, left) and encouraged families to count small toys (Figure 4, right).
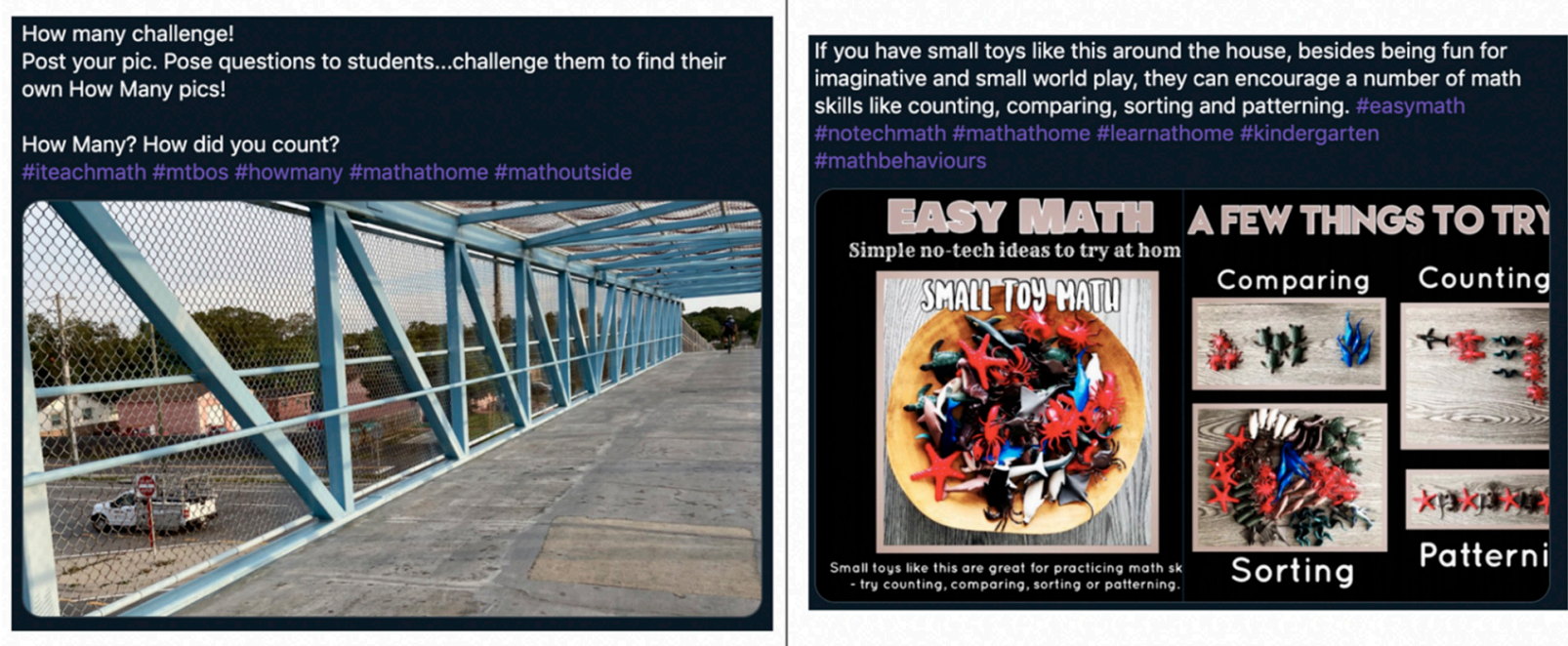

Figure 4. Tweets focused on counting using images and home-based objects.

Tweets about data and statistics, the second most common topic of \#mathathome tweets, largely emphasized categorizing and comparing, with some references to collecting and analyzing data or interpreting charts and tables online. A common activity prompted children to look at a set and decide which objects do not belong. Such activities, especially when accompanied with a press for justification, can encourage the development of comparing objects based on similarities and differences, and categorizing based on different criteria (Figure 5, left and Figure 4, right). Similar to counting, tweets about data and statistics offered opportunities for using resources directly available on Twitter or at home. For example, one parent leveraged the unique context of the pandemic to encourage data collection and analysis of personal protective equipment (mask-wearing) behavior (Figure 5, right). 


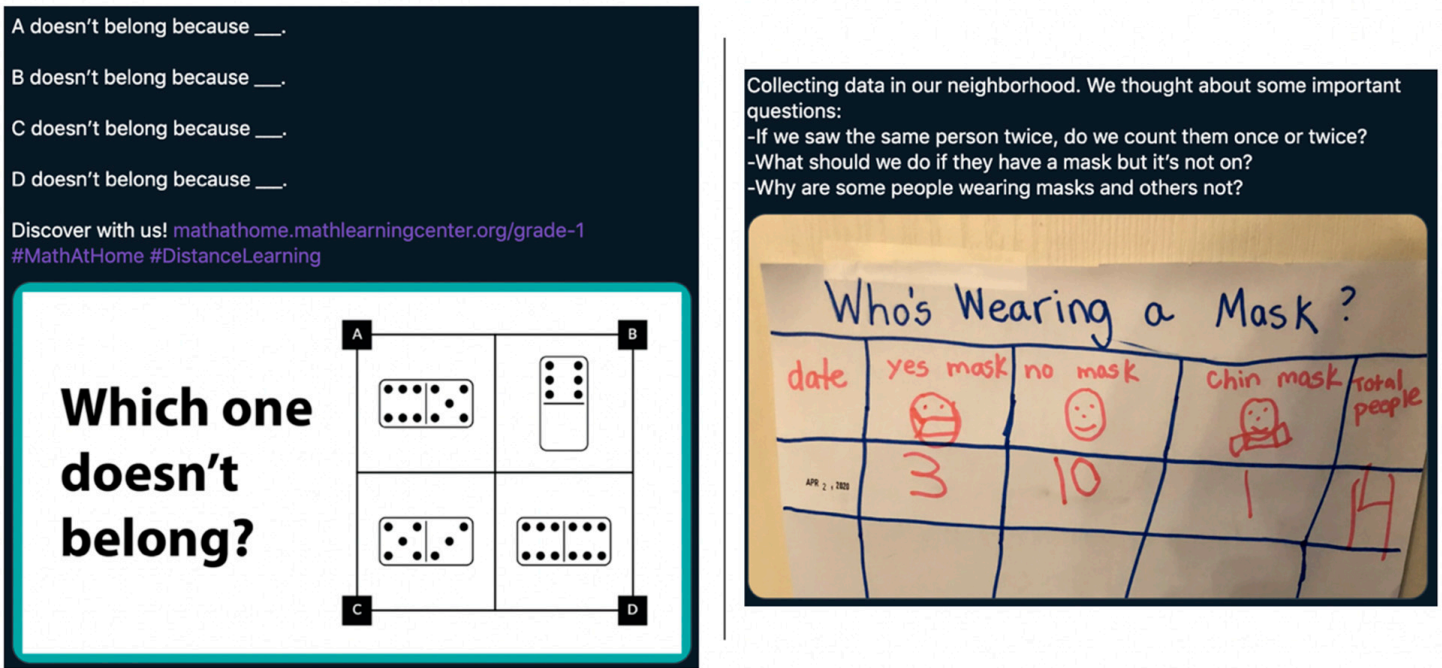

Figure 5. Tweets emphasizing categorizing, comparing, and statistics.

We describe only the most prominent subtopics for remaining content areas to provide insight into the nature of \#mathathome content (i.e., material capital). In geometry, tweets attended mostly to properties of two-dimensional shapes. For example, one tweet stated, "Caregivers, try some art with your children today using just triangles! Experiment with 'congruent' triangles (same shape and size), 'similar' triangles (same shape, diff size), or use completely different triangles!" Tweets about four operations mostly included addition and subtraction, many with videos or photographs of teacher-led activities (Figure 6, top left); and the focus on fractions mostly emphasized the part-whole relationship and equivalence (e.g., "How many ways can you show 3/8?; and Figure 6, top right). In algebra, opportunities overwhelmingly emphasized generalizing patterns of growth. For example, using multiplicative reasoning to predict the number of petals on $3,4, \ldots 10$ flowers (Figure 6, bottom center). Measurement tweets encouraged both standard and non-standard units to measure length (Figure 6, bottom left), temperature, time, volume, and weight (especially in cooking). Finally, only one tweet addressed calculus (Figure 6, bottom right).

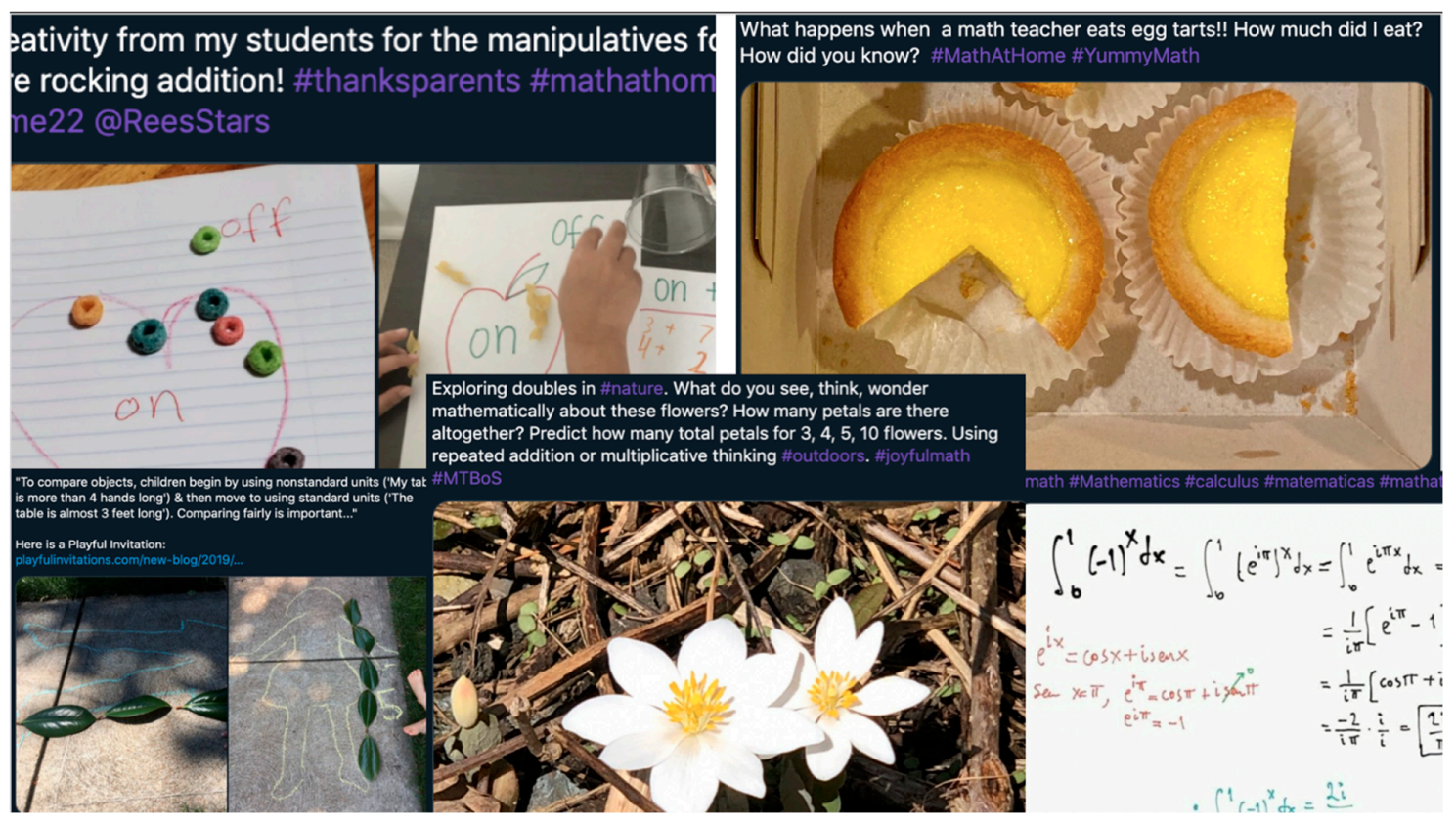

Figure 6. Examples Addition, Fractions, Measurement, Algebraic Reasoning, and Calculus. 
Many tweets encouraged the use of everyday objects or activities as opportunities to engage with a range of mathematics topics. For example, one of the most active educational organizations (with a centrality of 296, indicating this organization initiated or received this many interactions through \#mathathome) supported data and statistics, four operations, fractions, geometry, measurement, and number through activities such as doing physical activity, estimating and measuring everyday objects, playing shop, and counting, sorting and describing groceries. Moreover, many tweets emphasized developing mathematical practices necessary for sense-making (beyond straightforward procedures). Such practices included explanation and justification, such as justifying categorizations (Figure 5, left) and answering, "How did you know?" (Figure 6, top right). In other cases, the openended nature of problems encouraged students to engage multiple strategies; for example, defining units and counting in different ways (Figure 4, left), categorizing based on different criteria (Figure 4, right and Figure 5, left), and using different strategies to generalize growth patterns (Figure 6, bottom center).

\subsubsection{Mathematical Focus in Survey}

In response to a question about mathematics activities (i.e., material capital), parents shared a myriad of ways they supported mathematics at home. Similar to what we found from our analysis of \#mathathome tweets, parents emphasized cooking, budgeting, solving real-world problems, and incorporating everyday experiences into their child's mathematics learning. Named activities included several mathematics topics: measurements (e.g., time, volume, temperature), operations with money (e.g., addition, subtraction, money value), and counting (mainly counting manipulatives or objects). Lists such as these were typical: "Cooking measurements/fractions, shopping prices and percent, measuring length [with] sewing/crafts," and "Fractions, baking, counting money." Identified mathematics topics overlapped with those addressed by tweets. Moreover, parents discussed how they asked for justification and multiple solutions when doing mathematics. For example, one parent shared, "Often effective is getting my child to explain what he is learning to me. If he can tell me what he's trying to do, then sometimes I can ask clarifying questions." In contrast to tweets, some mathematics topics were underrepresented in survey responses. For example, only two replies highlighted geometry: "Cutting things into pieces ... naming shapes," and "Naming shapes properly when playing with his blocks/toys." Moreover, only one response indicated using statistics as a way of supporting mathematics learning at home: "We talk about stats and maths as part of daily life but I don't deliberately have maths conversations with [my children]".

\subsubsection{Responses to and Resources during COVID-19}

Survey responses shed light on the types of resources provided by both schools (i.e., capital within school space) and parents (i.e., capital within home/community space) to support continued mathematics education at home (RQ1). The most common school/ district emergency response to COVID-19 (according to our respondents) was online instruction completed asynchronously and without a teacher $(n=86)$, including online activities and instructional videos. The next most common response involved instruction through offline worksheets $(n=47)$. As these responses indicated, some schools provided multiple forms of emergency remote instruction. Opportunities for synchronous instruction were less common: online class with teacher and classmates $(n=42)$ and opportunities to learn with a teacher online or by phone $(n=39)$. Only one parent indicated receiving no instructional support from their child's school.

Schools used a range of online learning management systems or applications used inpart or entirely for providing emergency remote instruction. Google Classroom $(n=60)$ and Zoom $(n=31)$ were the most commonly used. Other notable platforms included: SeeSaw $(n=22)$, Class Dojo $(n=17)$, and Flipgrid $(n=9)$. Parents also reported receiving a range of resources from schools to support mathematics learning, and most said they used the provided resources at least sometimes $(n=98)$. As instructional responses suggest, the most 
common resources included online activities $(n=71)$, mathematics instructional videos for children $(n=47)$, and offline worksheets $(n=36)$. Other resources included: laptops, tablets or other devices $(n=37)$, books $(n=12)$, mathematics manipulatives $(n=11)$, mathematics instructional videos for parents $(n=9)$, internet access $(n=8)$, and calculators $(n=4)$. Only four parents reported receiving no resources from the school. Parents supplemented school-based instruction and resources (i.e., material capital in home/community space) by providing necessary laptops or other devices $(n=72)$ and internet access $(n=80)$ for continued mathematics education. Parents also provided: mathematics manipulatives $(n=44)$, calculators $(n=36)$, online resources that helped them and their children understand mathematics ( $n=32$ and $n=36$, respectively), additional worksheets or problems $(n=29)$, and books $(n=20)$. Six parents reported providing no additional resources.

Survey responses addressed what parents most needed to continue mathematics education at home (i.e., to mediate different forms of capital across spaces). For some parents, emergency remote instruction worked well. For example, one parent elaborated:

My son's math teacher did an outstanding job working remotely with him during lockdown. This is by far his weakest subject ... Once I reached out to [the teacher] about the amount of time I was spending with him-she upped her individual tutorials with him ... Since then, he's been able to work virtually independently ... I think that the mini-tutorials [synchronous video] have been an outstanding success.

Other parents, however, described drastically different experiences: "I feel abandoned by ... my husband and I work full-time. We are not equipped to try to teach a 7 year old math, reading, etc. The worksheets didn't cut it".

Almost every parent (of the 84 who wrote an open-ended response) mentioned desiring greater synchronous instructional time with their children's teacher. For example, one respondent said they would like, "structured online learning at a set time with teachers trained to teach online." Moreover, parents wanted more "set math lessons rather than just activities" and more guidance to help them aid their child's mathematics learning at home. For example, one respondent wanted teachers to "provide clear, concise instructions so that parents and students are not trying to solve a puzzle of complicated, not-comprehensive instructions to complete math assignments." Some parents suggested video tutorials to aid both their own and their child's understanding of the mathematics concepts (which some but not all teachers provided). Finally, a few parents requested differentiated assignments, noting, "Some of the work is too easy for [my child] and some is too hard for him." Next, we look across and discuss the implications of these and our other key findings in the next section.

\section{Discussion}

Findings from this mixed methods study support the emerging notion that COVID-19 acted as a mediating event that changed the nature of parental engagement in mathematics education [36]. Parental engagement in mathematics at home during emergency remote instruction was high, and the transition to school mathematics at home prompted some parents to increase involvement (e.g., "Until COVID-19, I typically avoided helping her ... "). Such an increase is likely explained by the fact that most schools and districts initially responded to COVID-19 by providing mathematics activities done without direct involvement from children's teachers.

We must view findings with some caution, however, given that those already engaged in mathematics on Twitter and those who volunteered to respond to a survey about mathematics at home are more likely to indicate high levels of involvement. Moreover, survey respondents were highly educated and included mathematics educators because of the sampling methods. In this way, the individuals we studied were a select group, which, in this case, may indicate that what we found may be closer to an upper-bound (rather than an average) level and type of parental engagement with mathematics at home during the pandemic. Nonetheless, interpreting findings in relation to existing literature 
suggests that the experiences of parents described by our analyses likely provide insights into typical mathematics experiences during COVID-19 emergency remote instruction. Moreover, studies from around the world (e.g., Norway, Indonesia, Nigeria), which focused on broader educational experiences, showed a similar increase in parental involvement in schooling during the initial transition to remote instruction [23,37-40]. Looking across findings from recent studies on parents' experiences with emergency remote instruction during the early stages of COVID-19 suggests that our findings have broader implications despite the large number of participants from the United States.

When parents are explicitly invited to engage in school mathematics, research suggests that they do so, regardless of race/ethnicity or education attainment level [11,13,14,41,42], and our findings confirmed a similar response from parents in the face of emergency remote instruction-which increased expectations for school mathematics at home. Such findings prompt initial optimism about the potential for sustaining high levels of parental engagement in school mathematics, which can promote higher levels of mathematics achievement [8], beyond the COVID-19 crisis [36]. Researchers in Norway also reported that emergency remote instruction provided greater opportunities for creative tasks within the school curriculum, especially for younger students; for teacher feedback through digital platforms; and for student independence to develop [38].

While optimism is important during such a challenging moment, findings also point to the significant barriers that parents faced (e.g., "I feel abandoned ... ")—and still face. Parents in our study and others reported struggling to manage the increased responsibilities [23,43]. Higher levels of parental engagement and the transition of school-based materials and resources into the home - out of necessity — may not be sustained throughout or beyond the pandemic and may result in widening inequities in mathematics opportunities and achievement. Disparities in access to digital technology especially threaten to widen educational inequality $[37,44]$. Moreover, as our study also confirmed (given the large number of women respondents in our survey) and as others have noted [21,39], women largely took on the added responsibilities of continuing education in the home during emergency remote instruction. Implications from these findings must be acknowledged and addressed in order to disrupt potentially deepening educational and social disparities.

In the context of our key finding about the different ways in which parents and caregivers became involved with children's education at home, we next discuss implications and offer some recommendations for more effectively supporting parental engagement during and beyond the COVID-19 pandemic. Given the lack of attention to parental engagement in e-learning [23] and the limited focus in mathematics education, specifically, this study contributes new insights into sustaining increased parent engagement in mathematics education, easing the burden of managing emergency remote instruction in the home, and addressing the potential for rising educational inequality due to COVID-19.

\subsection{Renewing to Efforts to Engage Parents}

A tradition of excluding parents from conversations about school mathematics plagues mathematics education [45]. The result often pits schools, teachers, and parents against each other rather than fostering partnerships for children's mathematics learning (e.g., "math wars" [46]). Differences between parents' own mathematics education (which for many emphasized rules and procedures [11]) and the curriculum and instruction experienced by their children present barriers to parental involvement [16], and this challenge was only intensified by COVID-19. Parents and children alike experienced increased anxiety during emergency remote instruction [37,47], and likely even more so in mathematics. For example, consider these memes from our initial exploratory data generation (Figure 7), which show parents' frustration with supporting their children with unfamiliar problem-solving approaches. 
Day 1 with a 6 th grader and 4th grader and I need google to help them with their Math

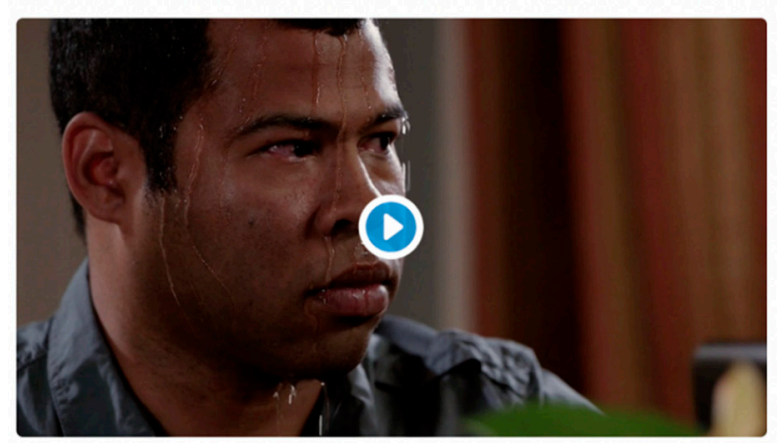

Home school teacher don't play that. \#TuesdayMotivation

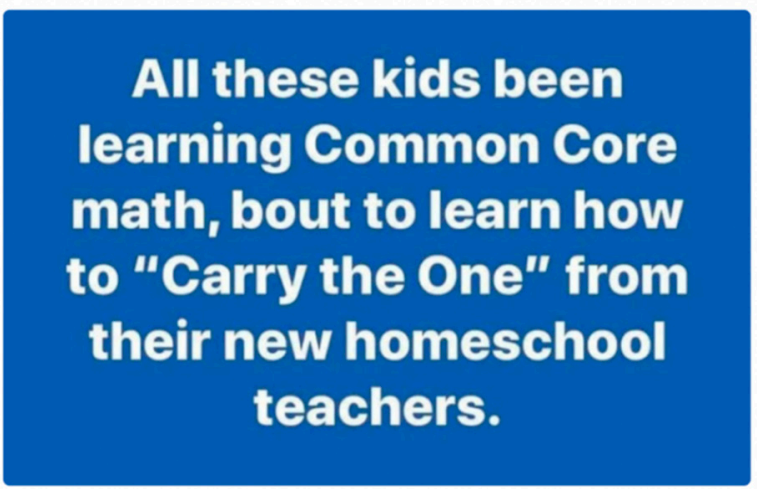

Figure 7. Memes during early transition to emergency remote instruction.

Survey responses provided insights into sources of frustration (e.g., "Doing math at home has been brutal"). For example, 86 of 101 (85\%) respondents indicated expectations for children to complete work without teachers' direct involvement. This finding suggests, and other studies confirm $[39,40]$, that parents were largely expected to bear the burden of continuing students' mathematics learning, but in ways that aligned with school-provided materials. Some schools provided additional support to help parents understand how mathematics education has evolved (e.g., online resources for parents' mathematics understanding, $n=32$ ), but most parents in our study reported limited support. Limited understanding of school mathematics caused some parents to restrict their involvement, even during emergency remote learning (e.g., "I don't want to interfere in his method"). Even parents who are also mathematics teachers reported little familiarity with specific grade-level mathematics (e.g., I “don't necessarily know what is developmentally appropriate for my Kindergartener"). During a time of such disruption to children's education, a history of devaluing parental engagement in the evolution of mathematics education left parents feeling "abandoned."

As an implication of these circumstances, the mathematics education community must take more seriously commitments to include parents in the process of evolving and even revolutionizing school mathematics. Renewed efforts are needed to bridge parents' and children's experiences with mathematics education. Research suggests that parents benefit from developing mathematics content and pedagogical knowledge much in the same way that teachers do [7] and that opportunities to re-engage with mathematics can bolster parental engagement $[12,16]$. Helping parents understand the evolution of school mathematics would support their own children's mathematics education and also allow them to be allies for other parents [17] and teachers who may be over-extended during times of crisis (e.g., creating instructional videos, providing one-on-one tutorials). In the next section, we discuss possibilities for how we can build bridges for necessary conversations.

\subsection{Reimagining How Parents Engage}

While some attention has been paid to the importance of inviting multiple stakeholders to participate in conversations about teaching, learning, and educational systems [48,49], parents' input and voices are not commonly recognized. In light of disruptions to mathematics education due to the COVID-19 pandemic, parental engagement may be more important than ever-particularly for parents from marginalized groups [10,11]. Social media (and other digital spaces) present new opportunities for parents to mediate their engagement in multiple ways (e.g., accessing announcements and resources posted by teachers, schools, and districts; sharing resources they create for children). However-as 
we found in this study - such opportunities may be under-utilized by (or not widely known to) parents.

We see social media and other online platforms as a particularly promising way to include parents in conversations about mathematics education because parents are already relying on online resources to support emergency remote instruction. COVID-19 triggered a notable increase in demand for online learning resources (four times more compared to pre-pandemic) [44], and parents sought out both school-sanctioned online platforms and supplemental resources (as shown in our findings). Searches for online educational resources, however, increased as family socioeconomic status increased, which is alarming because parent searches for such online resources correlated with students' mathematics progress [44].

Promoting educational resources on more widely available online platforms may help address disparities by creating a widely available space for parents to mediate human, social, and material capital for engagement. Yet, our survey findings suggested that most parents were not aware of opportunities for mathematics education on social media (e.g., "I was not aware this was a thing people do"). This finding is bolstered by those from our analysis of the \#mathathome hashtag on Twitter: Parents comprised a very small proportion of those actively using the hashtag ( 3 of 46 , or $6 \%$ ), with most participants instead identifying as educational organizations, teachers, and instructional coaches or administrators. These findings, then, collectively point to a potential missed opportunity to involve parents in their children's education through technology-based platforms-especially social media, which is purported to be open and accessible to a range of those invested in children's education [50,51].

In this way, this study invites greater attention to the role and potential importance of involving a key stakeholder-parents-in mathematics education on social media platforms, which we consider to be one implication of our analysis of both Twitter- and survey-based data related to mathematics at home. One way to involve parents in conversations about mathematics education using online platforms would be for teachers to explicitly invite them to participate $[13,41]$. Findings suggest that YouTube, Facebook, and Pinterest, followed by Twitter are platforms that parents already use, and which therefore may be suitable targets for such invitations. Failing to involve parents may contribute to conversations about the evolution of mathematics education taking place without their input, as teachers and others increasingly use social media as a space for engaging in discussions about educational change and transformation efforts [52]. Additionally, continuing to talk at, rather than with, parents, in spaces like Twitter can be compared to how teachers withhold physical resources (e.g., textbooks) from Black families with low-income backgrounds due to racial stereotypes about families' interest in parental engagement and ability to care for materials [11]. Though parents from low-income and racial minorities may have more limited access to technology in the home [20,37,53], educators should resist stereotypes about parents' willingness and ability to engage in mathematics education in online spaces.

Lastly, we note that in the midst of the widespread use of social media [54], instead of turning to social media-based online resources and allies, parents overwhelmingly reported turning to their child's teacher as an ally, with 76 of our 101 (75\%) of survey respondents indicating that they had done so. This suggests that despite the social distancing required in response to COVID-19, parents turned to those with whom they had already-established relationships, and, potentially, trust, which may be more importantrather than less so or irrelevant in light of ample use of social media [54]—during times of crisis. High-income families reported increased use of online educational resources [44] and a general satisfaction with school support [43] during COVID-19 emergency remote instruction. This suggests that increasing access to various forms of human and social capital is especially salient for supporting families marginalized in and by mathematics in both times of crisis and in general. 


\subsection{Broadening Mathematical Focus}

Finally, findings point to a need to broaden opportunities for the types of mathematics engagement accessible to parents and families. Across Twitter and survey data, elementary mathematics content was emphasized. Other researchers also noted that parental engagement during emergency remote instruction was especially high among parents of younger children $[23,38,43]$. The over-emphasis on elementary mathematics suggests that limited opportunities for parental engagement are available in online spaces, such as Twitter. Although we found a range of mathematics topics across tweets, hashtags familiar to parents in our survey echoed the dominance of counting (\#unitchat) and categorizing/comparing (\#WODB). Research on parental engagement also focuses heavily on parents of elementaryaged children, e.g., $[7,11,16]$. Consequently, much of what is known about supporting parents to understand the evolution of school mathematics [7] or to bridge school mathematics and home/community mathematics [55] is useful only for engaging parents of young children. Broadening opportunities for parents of older students to engage in mathematics education is important because the correlation between parental involvement and academic achievement is stronger in upper grade levels [23]. As the mathematics education community renews commitments to include educators and parents in conversations about school mathematics, attention must be paid to welcoming involvement from parents of older students, and students themselves.

In addition to broadening mathematical focus by grade level, a need also exists to broaden the nature of mathematics in which parents and children engage together. Attempts to artificially separate the school space of remote instruction from the context in which it occurred (the home), positioned parents as learning managers, tasked with creating distinct spaces for play and for learning within the home [40]. This positioning of parents is problematic because parental control (versus engagement) has been linked to low mathematics performance, task persistence, and mathematics self-concept [56]. Instead of positioning parents as learning managers, schools and educators might seek to support parents as they author a hybrid space that promotes learning school mathematics topics through home-based activities, e.g., [55]. Our findings from both the survey responses and Twitter analysis provide some examples from emergency remote learning (e.g., cooking; Figure 6). In other words, the human, social, and material capital necessary for parents to navigate their own experiences with mathematics compared to contemporary instructional approaches exist, and parents made promising efforts to leverage those resources to author a productive home-school space during emergency remote learning. A next step might focus on how teachers and schools can foster and develop these initial efforts. Successful models from emergency remote instruction that directly involved schools, for example, could provide useful insights into promoting creative mathematics engagement that aligns with the school curriculum at home, e.g., [38].

A final implication of our findings is the need to consider which digital tools best support creativity and problem solving when school mathematics occurs within the home. In addition to social media as a way for parents to engage in conversations with educators, researchers, and others about the evolution of school mathematics (i.e., social and human capital) and to access home-based mathematics activities (i.e., material capital), a range of digital tools exist that make mathematics more accessible to a wide audience (i.e., material capital). Extant research focuses on how these digital tools support mathematics teaching and learning in the classroom setting, e.g., [57-60]. This research emphasizes the importance of matching the digital tool to the educational application, which demands flexibility in the design and use of these tools [57]. Moreover, research shows the importance of synthesizing the instruction provided by the teacher and by the digital tool [58]. In other words, the digital tools that are effective in the classroom may not promote the same type of creativity and problem solving in mathematics within the home setting, especially if parents' instruction contradicts instruction from teachers and/or digital tools.

Looking to some especially promising and flexible models of digital tools might help teachers and parents reimagine and co-author a hybrid space that connects home- and 
school-based ways of doing mathematics. For example, the Digital Mathematics Environment is an online environment that would allow teachers to customize mathematics activities based on the unique home-based resources and experiences of their students [57]. Other models show how digital tools can support gamification in mathematics (e.g., escape rooms), which can also promote creativity, motivation, and achievement for both primary [38] and secondary students [59,60]. Future research is needed to explore the possibilities for using digital tools, that have shown effective in the classroom, to support creativity and problem-solving in school mathematics at home.

\section{Conclusions}

As we were analyzing the data for this manuscript, protests against police brutality and racial injustice erupted in over 140 U.S. cities and in displays of solidarity around the world [61,62]. These protests highlighted how many communities live in a perpetual state of crisis in addition to and in amplification of those crises due to the COVID-19 pandemic. Although a public health crisis presents unique challenges, some of which this study shed light on - families already marginalized in and by mathematics and women felt the weight of the disruptions caused by COVID-19 disproportionately. In other words, for many families, mathematics education during a time of crisis will persist even as and after the pandemic fades, and this demands attention in future research and educational initiatives. Our study provided only limited understanding of the unique lived experiences of mothers and caregivers from marginalized groups, and we urge the community to continue to imagine new possibilities for learning and doing mathematics beyond the possibilities we have suggested to value the voices of parents and families-particularly those shunned in and excluded from education and society. With such widespread parental engagement and disruptions in educational systems due to COVID-19, new doors have opened for both educational inequality and educational reform, and the time to choose the path of evolving and revolutionizing mathematics education is now.

Author Contributions: Conceptualization, F.K.H.; Methodology, F.K.H. and J.M.R.; Validation, F.K.H., J.M.R., S.C., K.H., S.W.; Formal Analysis, F.K.H., J.M.R., S.C., K.H., S.W.; Investigation, F.K.H., J.M.R., S.C., K.H., S.W.; Data Curation, F.K.H. and J.M.R.; Writing-Original Draft Preparation, F.K.H., J.M.R., S.C., K.H., S.W.; Review and editing, F.K.H. and J.M.R.; Visualization, F.K.H. and J.M.R.; Supervision, F.K.H.; Project Administration, F.K.H.; Funding Acquisition, F.K.H. The third, fourth, and fifth authors contributed equally to the manuscript. Their names are listed alphabetically to reflect equal contribution. All authors have read and agreed to the published version of the manuscript.

Funding: This research was funded, in part, by the Office of Community Outreach and Engagement, the 1794 Scholars Program, and the Office of Undergraduate Research at the University of Tennessee, Knoxville.

Institutional Review Board Statement: The study was conducted according to the guidelines of the Declaration of Helsinki, and approved by the Institutional Review Board of University of Tennessee, Knoxville (protocol IRB-20-05859-XM; 14 May 2020).

Informed Consent Statement: Informed consent was obtained from all subjects involved in the study.

Data Availability Statement: Data are available by request from the corresponding author.

Conflicts of Interest: The authors declare no conflict of interest.

\section{References}

1. Center for Disease Control and Prevention. Coronavirus Disease 2019 (COVID-19): Frequently Asked Questions. Available online: https: / /www.cdc.gov / coronavirus /2019-ncov / faq.html (accessed on 18 September 2020).

2. Coronavirus Resource Center. New Cases of COVID-19 in World Countries. Available online: https://coronavirus.jhu.edu/data/ new-cases (accessed on 6 October 2020).

3. UNESCO. COVID-19 Impact on Education. Education: From Disruption to Recovery. Available online: https://en.unesco.org/ covid19/educationresponse (accessed on 9 October 2020).

4. National Council of Teachers of Mathematics (NCTM). Catalyzing Change in High School Mathematics: Initiating Critical Conversations; NCTM: Reston, VA, USA, 2018; ISBN 978-1-68054-014-7. 
5. NCTM. Catalyzing Change in Middle School Mathematics: Initiating Critical Conversations; NCTM: Reston, VA, USA, 2020; ISBN 9781-68054-044-4.

6. Henderson, A.T.; Mapp, K.L. A New Wave of Evidence: The Impact of School, Family, and Community Connections on Student Achievement; Southwest Educational Development Lab: Austin, TX, USA, 2002.

7. Knapp, A.; Landers, R.; Liang, S.; Jefferson, V. We all as a family are graduating tonight: A case for mathematical knowledge for parental involvement. Educ. Stud. Math. 2017, 95, 79-95. [CrossRef]

8. Yan, W.; Lin, Q. Parent involvement and mathematics achievement: Contrast across racial and ethnic groups. J. Educ. Res. 2005, 99, 116-127. [CrossRef]

9. Copping, K.E.; Kurtz-Costes, B.; Rowley, S.J.; Wood, D. Age and race differences in racial stereotype awareness and endorsement. J. Appl. Soc. Psychol. 2013, 43, 971-980. [CrossRef] [PubMed]

10. Barton, A.C.; Drake, C.; Perez, J.G.; St. Louis, K.; George, M. Ecologies of Parental engagement in urban education. Educ. Res. 2004, 33, 3-12. [CrossRef]

11. Jackson, K.; Remillard, J.T. Rethinking parent involvement: African American mothers construct their roles in the mathematics education of their children. Sch. Community J. 2005, 15, 51-73.

12. Martin, D.B. Mathematics learning and participation as racialized forms of experience: African American parents speak on the struggle for mathematics literacy. Math. Think. Learn. 2006, 8, 197-229. [CrossRef]

13. Civil, M.; Planas, N.; Quintos, B. Immigrant parents' perspectives on their children's mathematics education. ZDM Int. J. Math. Educ. 2005, 37, 81-89. [CrossRef]

14. Smith, J.; Wohlstetter, P.; Kuzin, C.A.; De Pedro, K. Parent involvement in urban charter schools: New strategies for increasing participation. Sch. Community J. 2011, 21, 71-94.

15. Civil, M.; Guevara, C.; Allexsaht-Snider, M. Mathematics for parents: Facilitating parents' and children's understanding in mathematics. In Proceedings of the 24th Psychology of Mathematics Education North American Meeting (PMENA 24), Athens, GA, USA, 26-29 October 2002; pp. 1755-1766.

16. Muir, T. Numeracy at Home: Involving Parents in Mathematics Education. Int. J. Math. Teach. Learn. 2012, 25, 1-13.

17. Civil, M.; Bernier, E. Exploring images of parental participation in mathematics education: Challenges and possibilities. Math. Think. Learn. 2006, 8, 309-330. [CrossRef]

18. Hodges, C.; Moore, S.; Lockee, B.; Trust, T.; Bond, A. The Difference between Emergency Remote Teaching and Online Learning. Available online: https:/ / er.educause.edu/articles/2020/3/the-difference-between-emergency-remote-teaching-and-onlinelearning (accessed on 1 April 2020).

19. Eligon, J.; Burch, A.D.S.; Searcey, D.; Oppel, R.A. Black Americans Face Alarming Rates of Coronavirus Infection in Some States. The New York Times [Online] (7 April 2020). Available online: https://www.nytimes.com/2020/04/07/us/coronavirus-race. html (accessed on 9 October 2020).

20. Wang, J.; Moghadam, S.H. Diversity barriers in K-12 computer science education: Structural and social. In Proceedings of the 48th ACM Technical Symposium on Computing Science Education (SIGCSE 2017), Seattle, WA, USA, 8-11 March 2017; pp. 615-620.

21. Power, K. The COVID-19 pandemic has increased the care burden of women and families. Sustain. Sci. Pract. Policy 2020, 16, 67-73. [CrossRef]

22. Panchal, N.; Kamal, R.; Orgera, K.; Cox, C.; Garfield, R.; Hamel, L.; Muñana, C.; Chidambaram, P. The Implications of COVID-19 for Mental Health and Substance Use. Available online: https:/ /www.kff.org/coronavirus-covid-19/issue-brief/ the-implications-of-covid-19-for-mental-health-and-substance-use/\#: \{\{\}:text=Research $\% 20$ shows $\% 20$ that $\% 20$ job $\% 201$ loss, substance\%20use\%20disorder\%20and\%20suicide (accessed on 21 August 2020).

23. Panaoura, R. Parental involvement in children's mathematics learning before and during the period of COVID-19. Soc. Educ. Res. 2020, 2, 65-74. [CrossRef]

24. Fetters, M.D.; Curry, L.A.; Creswell, J.W. Achieving integration in mixed methods designs-principles and practices. Health Serv. Res. 2013, 48, 2134-2156. [CrossRef]

25. NCapture for NVivo 12 for Mac; QSR International: London, UK, 2020.

26. Lieber, E.; Weisner, T.S.; Taylor, J. Dedoose; SocioCultural Research Consultants, LLC: Manhattan Beach, CA, USA, 2020.

27. Hawksey, M. Need a Better Twitter Archiving Google Sheet? TAGS v6.0 is Here! Available online: https: / mashe.hawksey.info/ 2014/10/need-a-better-twitterarchiving-google-sheet-tags-v6-0-is-here/ (accessed on 9 October 2020).

28. Kearney, M. rtweet: Collecting and analyzing Twitter data. J. Open Source Softw. 2019, 4, 1829. [CrossRef]

29. R Core Team. R: A Language and Environment for Statistical Computing; R Foundation for Statistical Computing: Vienna, Austria, 2020.

30. Formplus. Eleven Demographic Survey Questions You Must Not Ask. Available online: https://www.formpl.us/blog/ demographic-survey-questions. (accessed on 15 April 2020).

31. Baltar, F.; Brunet, I. Social research 2.0: Virtual snowball sampling method using Facebook. Internet Res. 2012, 22, 57-74. [CrossRef]

32. Miles, M.B.; Huberman, A.M.; Saldaña, J. Qualitative Data Analysis: A Methods Sourcebook; Sage: Thousand Oaks, CA, USA, 2014; ISBN 9781506353074. 
33. Dorman, M. Mapsapi: Sf-Compatible Interface to Google Maps APIs; R Package Version 0.4.5. Available online: https://CRAN. R-project.org/package=mapsapi (accessed on 9 October 2020).

34. Greenhalgh, S.P.; Staudt Willet, K.B.; Rosenberg, J.M.; Koehler, M.J. Tweet, and we shall find: Using digital methods to locate participants in educational hashtags. TechTrends 2018, 62, 501-508. [CrossRef]

35. Rosenberg, J.M.; Greenhalgh, S.P.; Koehler, M.J.; Hamilton, E.; Akcaoglu, M. An investigation of State Educational Twitter Hashtags (SETHs) as affinity spaces. E-Learning and Digital Media 2016, 13, 24-44. [CrossRef]

36. Bakker, A.; Wagner, D. Pandemic: Lessons for today and tomorrow? Educ. Stud. Math. 2020. [CrossRef]

37. Azubuike, O.B.; Adegboye, O.; Quadri, H. Who gets to learn in a pandemic? Exploring the digital divide in remote learning during the COVID-19 pandemic in Nigeria. Int. J. Educ. Res. Open 2021. [CrossRef]

38. Bubb, S.; Jones, M. Learning from the COVID-19 home-schooling experience: Listening to pupils, parents/carers and teachers. Improv. Sch. 2020, 23, 209-222. [CrossRef]

39. Greenhow, C.; Lewin, C.; Staudt Willet, K.B. The educational response to Covid-19 across two countries: A critical examination of initial digital pedagogy adoption. Technol. Pedagog. Educ. 2020. [CrossRef]

40. Novianti, R.; Garzia, M. Parental engagement in children's online learning during COVID-19 pandemic. J. Teach. Learn. Elem. Educ. 2020, 3, 117-131. [CrossRef]

41. Anderson, K.J.; Minke, K.M. Parent involvement in education: Toward an understanding of parents' decision making. J. Educ. Res. 2007, 100, 311-323. [CrossRef]

42. Ortiz Lopez, C.; Donovan, L. Involving Latino Parents With mathematics through family math nights: A review of the literature. J. Lat. Educ. 2009, 8, 219-230. [CrossRef]

43. Garbe, A.; Ogurlu, U.; Logan, N.; Cook, P. COVID-19 and remote learning: Experiences of parents and children during the pandemic. Am. J. Qual. Res. 2020, 4, 45-65. [CrossRef]

44. Bacher-Hicks, A.; Goodman, J.; Mulhern, C. Inequality in household adaptation to schooling shocks: Covid-induced online learning engagement in real time. J. Public Econ. 2021, 193, 1-17. [CrossRef]

45. Allexsaht-Snider, M. Urban parents' perspectives on children's mathematics learning and issues of equity in mathematics education. Math. Think. Learn. 2006, 8, 187-195. [CrossRef]

46. Schoenfeld, A.H. The math wars. Educ. Policy 2004, 18, 253-286. [CrossRef]

47. Davis, C.R.; Grooms, J.; Ortega, A.; Rubalcaba, J.A.A.; Vargas, E. Distance learning and parental mental health during COVID-19. Educ. Res. 2020. [CrossRef]

48. Coburn, C.E.; Stein, M.K. Research and Practice in Education: Building Alliances, Bridging the Divide; Rowman \& Littlefield Publishers: Lanham, MD, USA, 2010; ISBN 0742564061.

49. Peurach, D.J.; Cohen, D.K.; Yurkofsky, M.M.; Spillane, J.P. From mass schooling to education systems: Changing patterns in the organization and management of instruction. Rev. Res. Educ. 2019, 43, 32-67. [CrossRef]

50. Greenhow, C.; Galvin, S.M.; Staudt Willet, K.B. What should be the role of social media in education? Policy Insights Behav. Brain Sci. 2019, 6, 178-185. [CrossRef]

51. Macià, M.; García, I. Informal online communities and networks as a source of teacher professional development: A review. Teach. Teach. Educ. 2016, 55, 291-307. [CrossRef]

52. Rosenberg, J.M.; Reid, J.W.; Dryer, E.B.; Koehler, M.J.; Fischer, C.; McKenna, T.J. Idle chatter or compelling conversation? The potential of the social media-based \#NGSSchat network for supporting science education. J. Res. Sci. Teach. 2020, 57, 1322-1355.

53. Warschauer, M.; Matuchniak, T. New technology and digital worlds: Analyzing evidence of equity in access, use, and outcomes. Rev. Res. Educ. 2010, 34, 179-225. [CrossRef]

54. Pew Research Center. Social Media Fact Sheet. Available online: https://www.pewresearch.org/internet/fact-sheet/socialmedia/ (accessed on 9 October 2020).

55. Civil, M. Everyday mathematics, mathematicians' mathematics, and school mathematics: Can we bring them together? J. Res. Math. Educ. Monogr. 2002, 11, 40-62. [CrossRef]

56. Silinskas, G.; Kikas, E. Parental involvement in math homework: Links to children's performance and motivation. Scand. J. Educ. Res. 2019, 63, 17-37. [CrossRef]

57. Drijvers, P. Digital tools in Dutch mathematics education: A dialectic relationship. In National Reflections on the Netherlands Didactics of Mathematics: Teaching and Learning in the Context of Realistic Mathematics Education; Van den Heuvel-Panhuizen, M., Ed.; Springer: Cham, Switzerland, 2020; pp. 177-195. [CrossRef]

58. Viberg, O.; Grölund, Å.; Andersson, A. Integrating digital technology in mathematics education: A Swedish case study. Interact. Learn. Environ. 2020. [CrossRef]

59. Jiménez, C.; Arís, N.; Magreñán Ruiz, A.A.; Orcos, L. Digital escape room, using Genial.Ly and a breakout to learn algebra at secondary education level in Spain. Educ. Sci. 2020, 10, 271. [CrossRef]

60. Curto Prieto, M.; Orcos Palma, L.; Blázquez Tobías, P.J.; Molina León, F.J. Student assessment of the use of Kahoot in the learning process of science and mathematics. Educ. Sci. 2019, 9, 55. [CrossRef] 
61. Cai, W.; Love, J.; Marsh, B.; Patel, J.K.; Parshina-Kottas, Y.; Ward, J. Protests over Racism and Police Violence. The New York Times [Online]. 31 May 2020. Available online: https:/ / www.nytimes.com/2020/05/31/us/george-floyd-protests-live-updates.html (accessed on 9 October 2020).

62. Rahim, Z.; Picheta, R. Thousands Around the World Protest George Floyd's Death in Global Display of Solidarity. CNN [Online]. 1 June 2020. Available online: https: / / www.cnn.com/2020/06/01/world/george-floyd-global-protests-intl/index. html (accessed on 9 October 2020). 